\title{
DITADURA, REDEMOCRATIZAÇÃO E APARTHEID NO BRASIL
}

\author{
Dictatorship, redemocratization and \\ apartheid in Brazil
}

\author{
Jerry Dávila*
}

\begin{abstract}
RESUMO
Este artigo examina o significado do apartheid na interpretação e contestação das relações raciais no Brasil no século XX, traçando uma evolução longe do projeto forjado por intelectuais e políticos de meados do século que criticaram o apartheid Sul-Africano a fim de promover uma auto-definição nacional positiva dos brasileiros. $\mathrm{O}$ artigo traça a apropriação da luta contra o apartheid pelo movimento dos direitos civis dos negros que emergiu no Brasil na década de 1980 e 1990 como uma ferramenta didática para traçar as linhas de discriminação racial e da desigualdade no Brasil. $\mathrm{O}$ foco do artigo sobre discurso brasileiro contra o apartheid permite um exame das mudanças na política racial brasileira, que inclui uma mudança da negação da existência do racismo (em comparação com a África do Sul) a um diagnóstico de discriminação racial (novamente auxiliado pela comparação com a África do Sul) e implantação de políticas de ações afirmativas para promover a inclusão.
\end{abstract}

Palavras-chave: ditadura; redemocratização; apartheid.

\begin{abstract}
This article examines the significance of apartheid in the interpretation and contestation of Brazilian race relations in the twentieth century, tracing an evolution away from a midcentury project by Brazilian intellectuals and politicians who criticized

* Ph.D. Universidade Brown e professor da Universidade de Illinois em Urbana Champaign (EUA), onde atualmente ocupa o cargo de Diretor do Lemann Institute for Brazilian
\end{abstract} Studies. E-mail: jdavila@illinois.edu 
South African apartheid in order to promote a positive national self-definition. The article traces the appropriation of the antiapartheid struggle by Brazil's emerging black civil rights movement in the 1980s and 1990s as a didactic tool for tracing the lines of racial discrimination and inequality in Brazil. The article's focus on Brazilian discourse about apartheid permits an examination of changes in Brazilian racial politics that includes a shift from the denial of the existence of racism (in comparison with South Africa) to a diagnosis of racial discrimination (again aided by comparison with South Africa) and deployment of raceconscious policies to promote inclusion.

Keywords: dictatorship; redemocratization; apartheid.

O preâmbulo da Constituição de 1988 afirma entre seus "princípios fundamentais" dois objetivos defendidos pelos poucos brasileiros negros que fizeram parte da Assembleia Constituinte: o dever da nova república "promover o bem de todos, sem preconceitos de origem, raça, sexo, cor, idade ou quaisquer outras formas de discriminação" (Tit. I, Art. 3-VI); e que nas relações internacionais, o Brasil seja guiado pelo "repúdio ao terrorismo e ao racismo" (Tit. I, Art. 4-VIII). Embora três das quatro constituições promulgadas no Brasil no século XX proibiram discriminação racial, esta foi a primeira vez em que a linguagem constitucional fosse largamente debatida e elaborada por constituintes autoidentificados como negros, e em diálogo com movimentos negros.

Mesmo assim esses delegados no constituinte entendiam essa linguagem como uma derrota: o conceito de repúdio internacional ao racismo perdeu a força de ação quando a Constituinte não aprovou o esboço do artigo que proibiria que o Brasil mantivesse relações diplomáticas, ou que empresas brasileiras entrassem em negócios, com países racistas, como a África do Sul. A Constituinte também rejeitou o esforço de definir discriminação racial e as penas legais a ser aplicadas. A deputada Benedita da Silva, uma das autoras da linguagem derrotada lamentou que "perdemos por 11 votos ... Defendiamos o rompimento com a África do Sul por conta do apartheid e da prisão do Mandela, detido pelo seu próprio povo, sem liberdade para defender suas idéias." O deputado Carlos Alberto Oliveira (Caó) comentou que "foi uma grande derrota porque, 
naquele momento, falar contra racismo no Brasil era também falar contra o apartheid."

Mas a inclusão daquela linguagem fez da Constituição de 1988 um divisor de águas na política racial brasileira no contexto da transição democrática que acabou com o mas extenso período de ditadura militar na América do Sul. A linguagem marca uma transição da construção preeminente nas meadas do Século XX que definia o Brasil como a antítese do racismo sul-africano. Onde políticos e intelectuais brasileiros tinham representado seu repúdio ao apartheid como mostra da ausência de preconceito racial no Brasil, na década de 1980, intelectuais e políticos negros que ganhavam espaço no processo de redemocratização começaram a usar comparações entre a África do Sul e o Brasil para chamar atenção à discriminação brasileira e reivindicar políticas compensatórias.

O engajamento brasileiro com a questão do apartheid passou por três fases. O primeiro veio depois da Segunda Guerra Mundial, quando figuras como Gilberto Freyre definiram o apartheid como moralmente incompatível com a cultura brasileira. Dentro da construção do Brasil como uma democracia racial, a África do Sul acompanhava os Estados Unidos como contraexemplos racistas do anti-racismo brasileiro. Curiosamente, intelectuais e políticos na África do Sul e nos Estados Unidos também investiram na contraimagem de um Brasil anti-racista para demonstrar que o supremacismo branco que predominava naqueles países não era normal nem inevitável e que caminhos alternativos existiam.

A segunda fase veio com o regime militar, que fez um jogo duplo: publicamente repudiava o apartheid para cultivar relações com países africanos, mas mantinha com a África do Sul seu principal circuito comercial no continente africano. O governo sul-africano procurou agilmente aprofundar esse comércio com o Brasil como parte de sua estratégia de driblar seu crescente isolamento internacional. Ao mesmo tempo, o governo brasileiro adotava medidas para diminuir seu alinhamento político com a África do Sul,

\footnotetext{
1 Isabela Vieira, "Movimento negro não conseguiu emplacar embargo à África do Sul na Constituinte," Agencia Brasil, 20 de novembro de 2008, (agenciabrasil.jusbrasil.com.br/noticias/219635/movimento-negro-nao-conseguiu-emplacar-embargo-aafrica-do-sul-na-constituinte)
} 
tais como evitar propostas de criar um acordo mútuo de defesa do Atlântico sul. A terceira fase veio com o processo de redemocratização, quando o movimento negro e cientistas sociais apropriaram a questão do apartheid como ferramenta para traçar as linhas da discriminação e desigualdade no Brasil. Virou comum, neste momento, sugerir que as relações raciais no Brasil eram piores que na África do Sul, onde brancos pelo menos assumiam publicamente seu racismo. Esta fase veio junto ao processo de desmoronamento do apartheid na África do Sul, um processo de mudança que brasileiros procuraram de acompanhar com mudanças nas políticas raciais brasileiras.

No início da década de 1960, o Brasil virou o primeiro país da América Latina a desenvolver relações com países africanos em processo de descolonização. Diplomatas e políticos brasileiros achavam que a África independente seria o polo comercial e geopolítico acima da qual o Brasil construiria sua potência mundial. Achavam que boas relações com o bloco afro-asiático emergente ajudaria à diplomacia brasileira a realizar objetivos como a conquista de uma vaga permanente no Conselho de Segurança da ONU. Achavam também que os novos países seriam mercados naturais para produtos produzidos pelo nascente polo industrial brasileiro (na década de 70, eletrodomésticos brasileiros foram comercializados na África como "tecnologia tropical" mais adequada as condições africanas). No processo de elaborar relações com países africanos, diplomatas brasileiros sempre reiteravam que o Brasil era uma democracia racial e enfatizavam laços culturais forjados pelo tráfico escravo (embora os diplomatas brasileiros eram, em sua quase totalidade, brancos). A crítica ao apartheid foi integral a estes esforços.

Os objetivos brasileiros na África eram, no fundo, inconsistentes e contraditórios, refletindo tensões e questões não resolvidas na sociedade brasileira. Enquanto o governo brasileiro procurava desenvolver relações com países independentes como a Nigéria, o governo continuava a apoiar o projeto colonial português em Angola e Moçambique. Mesmo que políticos e diplomatas brasileiros sonhavam com vastos mercados africanos para produtos brasileiros, os mercados de países africanos permaneciam fora do alcance da produção brasileira, que por sua vez carecia da capacidade 
de exportar em grande escala até meados da década de 70. Paradoxalmente, se a bens industriais brasileiros seriam um dia exportados para países africanos, a realidade imediata era que a indústria brasileira dependia de minerais sul-africanos com manganês, tungstênio e cromo. ${ }^{2}$

Até meados do 70, a África do Sul foi o principal parceiro comercial brasileiro, responsável por mais que a metade do intercâmbio brasileiro no continente. Não era coincidência que quando a empresa aérea Varig criou sua primeira rota para a África em 1969, voava entre Rio de Janeiro, Cidade do Cabo e Luanda. Este serviço aéreo, restrito a capitais de minoria branca e compartilhada por serviço recíproco pela South African Airways, passaram a ser um fato frequentemente citado por diplomatas africanos quando questionavam os compromissos brasileiros no continente.

Nos primeiros anos do regime militar brasileiro, temor do comunismo fez o governo se distanciar de regimes africanos que consideravam ideologicamente incompatíveis, e se alinhar ainda mais com a África do Sul, que usava um discurso de "defesa do ocidente" contra comunismo para esquivar pressões internacionais contra o apartheid. Em 1966, o chanceler Juracy Magalhães descreveu à plateia num discurso na Escola Superior de Guerra o aprofundamento das relações com a África do Sul, dizendo: "na minha conversa com o Ministro de Estado, Hilgard Muller, eu tive a oportunidade de explicar que nós brasileiros seguimos um caminho bastante diferente ao enfrentarmos o problema racial. Estávamos tão felizes com o caminho seguido que se tivéssemos de recomeçar, recomeçariamos com o mesmo rumo, mas nós respeitávamos a posição que eles adotaram. O apartheid é contrário a todos os sentimentos brasileiros; nós não desejamos que ele exista mas também nós não podemos querer impor uma decisão nossa contra a orientação e autodeterminação de outros países."3

2 Jacques D'Adesky, Jaques, "Intercâmbio comercial Brasil-África (1958-1977): Problemas e perspectivas," Estudos Afro-Asiáticos, 3 (1980): 5-34 and "Penetração brasileira na África Austral: Perspectivas políticas e entraves econômicos," Estudos Afro-Asiáticos, 10 (1984): 95-105.

3 "A política exterior do Brasil: Conferência pronunciada na Escola Superior de Guerra," Rio de Janeiro, 25 de julho de1966. JM pi Magalhães, J. 1966.07.25, Arquivo Juracy Magalhães, CPDOC/FGV. 
Por sua vez, o governo sul-africano elaborou uma política de procurar laços com o Brasil em áreas tão diversas quanto encontros esportivos, comércio e defesa mútua. Diplomatas sul-africanos atuaram com agilidade em relação a países sul-americanos para criar uma impressão generalizada da existência de fortes laços bilaterais, mesmo quando eles não existiam. Uma estratégia comum foi a de procurar um encontro informal entre chanceler da África do Sul e um chanceler sul-americano - talvez um jantar durante uma escala de voo. A reunião seria seguida por divulgação na imprensa sul-africana de suposto interesse brasileiro na criação de um acordo de defesa do Atlântico Sul semelhante ao OTAN. Essas reportagens seriam comentadas ou reproduzidas em outros países africanos. Mesmo desmentidos pelo governo brasileiro, esses boatos criavam a impressão da existência de acordos secretos entre os dois países. ${ }^{4}$

A ideia de um tratado de defesa do Atlântico Sul envolvendo alguma combinação de África do Sul, os Estados Unidos, Brasil, Argentina ou Uruguai, foi elemento chave da estratégia sul-africana de "outward movement" - movimento para fora. Como indica Andrew Hurrell, "um agrupamento militar no Atlântico Sul, mesmo que informal, tem sido visto [na África do Sul] como um elemento importante para desenvolver alianças e respeitabilidade, de ultrapassar o isolamento político do país, e de neutralizar a antipatia gerada pelo apartheid."5 Embora alguns estrategistas navais

4 Andrew Hurrell, "The Politics of South Atlantic Security: A Survey of Proposals for a South Atlantic Treaty Organization,” International Affairs 59, no. 2 (1983), 179-193, p. 180; Sobre relações brasileiras e argentinas com a África do Sul veja também Wayne Selcher, "Dilemas políticos nas relações Brasil-África: Comentário sobre alguns obstáculos políticos nas relações sulsul." Estudos Afro-Asiáticos, 10 (1984): 55-72; João Luís Ribeiro Fragoso, “As reformulações na política externa brasileira nos anos 70," Estudos Afro-Asiáticos, 5 (1981): 41-51.; Wolfgang Döpke, "Uma nova política exterior depois do apartheid? Reflexões sobre as relações regionais da África do Sul, 1974-1998," Revista Brasileira de Política Internacional, 41:1 (1998): 132-160; Ralph Lawrence, "South Africa and the South American Road to Democracy," South Africa International. 21:3 (1991): 173-181; Carlos Juan Moneta, "Aspectos Conflictivos de las Relaciones AfroLatinoamericanas. Las Vinculaciones Políticas, Economicas y Militares de Sudafrica con los Paises del Atlántico Sur Latinoamericano: El Caso Brasileño," Revista Argentina de Relaciones Internacionales., VI, nos. 16-17 (1980): 101-128; and Gladys Lechini de Alvarez, "O 'apartheid' e a política externa sul-africana: uma percepção a partir da Argentina," Estudos Afro-Asiáticos, 25 (1993): 251-274.

5 Hurrell, 180. 
brasileiros e argentinos se interessaram com a ideia, nunca foi seriamente debatido nos respectivos governos.

\section{A descolonização angolana e o apartheid}

Desde 1961, quando iniciou-se a guerra pela independência angolana, o regime português contou com o apoio dos governos do Brasil e a África do Sul a seu esforço de manter suas colônias africanas. Com a Revolução dos Cravos em Portugal em 1974, que iniciou o processo de democratização do país e resultou um ano depois na independência de Angola e Moçambique, alterou as relações externas do Brasil e da África do Sul.

Para o governo sul-africano, a descolonização portuguesa criou uma crise de segurança: as colônias portuguesas eram espaços de domínio branco que dava cobertura à África do Sul. Com a perda dessa proteção, a África do Sul adotou a "Total National Strategy" que incluiu a intensificação da repressão política e a violência na proteção do apartheid internamente. Em política externa, implicava incursões militares e apoio a facções simpáticas à África do Sul em Angola e Moçambique, com a finalidade de desestabilizar os novos países e evitar que esses países fronteiriços dessem apoio a movimentos contra o apartheid. Sob essa doutrina, o governo sulafricano ficou cada vez mais nas mãos de "securocrats" - burocratas da área de segurança - que intensificariam a repressão doméstica e realizariam invasões seguidas em Angola, aumentando o isolamento da África do Sul.

No Brasil, a independência angolana resultou em respostas muito diferentes. O governo brasileiro, que não tinha se distanciado do regime português antes de seu colapso, compensou ao ser o único país ocidental a reconhecer o governo marxista do MPLA em Angola. Depois da independência, mesmo dentro do contexto de guerra civil alimentado por incursões sul-africanas, o governo brasileiro manteve uma presença diplomática, forneceu assistência econômica ao novo governo, e ajudou a manter o sistema de abastecimento alimentar no 
país. A abordagem brasileira apoiou a estratégia de expandir mercados africanos para exportações de bens industrializados em países africanos, reduzindo o deficit comercial gerada pelo alto do preço do petróleo. Embora a África do Sul tinha sido o principal parceiro comercial do Brasil até meados da década de 70, ele seria superado na segunda metade da década pela Nigéria.

Com a mudança do eixo comercial brasileiro no continente africano, o governo brasileiro passou a se distanciar do governo sulafricano e ser mais veemente em suas críticas ao apartheid. O governo brasileiro procurou evitar colaboração cultural ou esportiva, limitar visitas diplomáticas, e obrigando políticos estaduais e municipais a submeter propostas de viajem a África do Sul - para onde foram frequentemente convidados - a aprovação pelo Itamaraty. Estas restrições respondiam, segundo o chanceler brasileiro Antônio Azeredo da Silveira, aos "esforços permanentes da representação diplomática sul-africana, contornando as restrições impostas pelo Governo brasileiro, para promover a participação, em eventos na República da África do Sul, de autoridades brasileiras não suficientemente informados do caráter do 'apartheid' e de nossa repulsa formal e oficial a essa política." Silveira explicou que "Através desse expediente, visa o Governo sul-africano a usar o nome do Brasil para dar a impressão de que não está tão isolado e que o regime do 'apartheid' não é tão universalmente repudiado." ${ }^{\text {"Uma }}$ ordem presidencial também pressionou empresas brasileiras importadoras de produtos sul-africanos a procurar mercados alternativos.

Em 1977, quando o Presidente Geisel e Silveira discutiram a possibilidade de enviar uma delegação brasileira a uma conferencia da ONU sobre racismo e apartheid, Silveira argumentou que perante o crescimento dos mercados africanos para produtos brasileiros, "Os próprios países africanos procuram maior aproximação com o Brasil, não apenas no campo comercial, mas também no econômico e político e esperam receber o apoio brasileiro na defesa das teses que

6 "Informação para o Senhor Presidente da República, Relações com a África do Sul. Convites a autoridades brasileiras," 20 de maio de 1977. AAS mre d 1974.03.26, vol. 26, CPDOC/FGV. 
contribuem para consolidar o seu processo de afirmação nacional. O combate à discriminação racial e ao racismo é uma dessas teses. Creio, assim, que no momento em que a comunidade internacional se reúne para debater a condenação ao apartheid, o Brasil não pode deixar de estar presente e demonstrar a sua solidariedade aos países africanos." 7

Mas no contexto do regime militar brasileiro, o repúdio ao apartheid não significou o reconhecimento da questão da igualdade racial dentro do Brasil. Pelo contrário, a rejeição do apartheid serviu como uma mostra da ausência de racismo no Brasil, e intelectuais e ativistas que assinalavam a existência de discriminação no Brasil sofriam represálias. Era o caso de Abdias do Nascimento, quem acompanhou a delegação estadunidense ao Festival de Artes e Culturas Negras (FESTAC) em Lagos, Nigéria em 1977. Em Lagos, ele denunciou as relações raciais brasileiras como talvez piores que na África do Sul. $^{8}$ A embaixada brasileira em Lagos respondeu às acusações de Nascimento com um esforço de barra-lo do FESTAC e pedindo que seja expulso da Nigéria - planos debatidos dentro do gabinete de Geisel.

Dentro do Brasil, ativistas negros estiveram sob vigilância. Paulina Alberto reconstrói o ativismo do movimento negro através de uma leitura dos registros do DEOPS, que incluem cópias do jornal SINBA, a qual, na primeira página de sua primeira edição, publicou uma entrevista com um líder estudantil em Soweto. Alberto traça a evolução da crítica ao apartheid no Brasil: no início, "não chegou a criticar o governo brasileiro. Mas aos poucos discussões sobre a África do Sul viraram uma ferramenta para deslegitimar e criticar a ideia de que o Brasil era uma democracia racial." Ativistas do movimento negro no Brasil evitavam críticas ao governo para evitar o tipo de perseguição sofrida por Nascimento. Neste ambiente, oposição ao apartheid criou um espaço para debater a discriminação no Brasil.

7 "Informação para o Senhor Presidente da República, Conferência das Nações Unidas sobre o Apartheid," 19 de junho de 1977. AAS mre d 1974.03.26, vol. 27, CPDOC/FGV.

8 Paulina Alberto, Terms of Inclusion: Black Intellectuals in Twentieth Century Brazil. Chapel Hill: University of North Carolina Press, 2011, p. 14.

9 Ibid, 264. 


\section{Apartheid e redemocratização}

Durante a década de 1980, a abertura política deu espaço político ao Movimento Negro Unificado, conselhos municipais e estaduais para a defesa de comunidades negras, e a mobilização política negra dentro do PDT e o PT. Para a geração política que engajou questões de relações raciais dentro da abertura, um desafio consistente foi a de conseguir que políticos com discursos antiracistas tomassem ações que refletissem sua retórica. Por exemplo, se o apartheid sul-africano era tão fácil de denunciar, por que era tão difícil tomar medidas como o rompimento de relações diplomáticas com a África do Sul, ou a implantação de sanções econômicas contra o regime?

Os poucos negros que começaram a ganhar espaço político, como Caó, Abdias do Nascimento, Benedita da Silva e Hélio Santos, enfrentaram muita dificuldade em avançar projetos do movimento negro, como a criação do Dia Nacional da Consciência Negra. Mas o processo de redemocratização no Brasil aconteceu ao mesmo tempo em que a mobilização de desobediência civil negra na África do Sul desafiou intensamente as políticas de segurança nacional que sustentavam o regime do apartheid. A mobilização contra o apartheid recebeu ampla atenção na imprensa brasileira. A crescente atenção ao apartheid criou espaço para debater relações raciais no Brasil e para definir o direito à igualdade para negros no Brasil como um elemento dos direitos humanos.

Em 1985, o Presidente Sarney impôs algumas sanções limitadas contra a África do Sul. O decreto baniu a venda de combustível e armas e proibiu a participação brasileira em eventos esportivos sul-africanos. José Maria Nunes Pereira argumenta que as sanções tinham menos a ver com pressões vindas de dentro do Brasil e mais com os interesses diplomáticos e comerciais do governo brasileiro em Angola e Moçambique. Para Pereira, essas medidas contrariaram a pressão política: em 1987, com a coligação de 310 deputados federais e 45 senadores - a Frente Anti-Apartheid - pediu a Sarney o rompimento de relações. Uns meses depois, o bispo Desmond Tutu visitou o Brasil e fez o mesmo pedido. A tentativa de 
Benedita da Silva e Caó de integrar na Constituição a obrigação de romper relações com países racistas também fracassou. ${ }^{10}$

Dentro do Brasil, os opositores do apartheid também enfrentaram o poderoso lobby político da empresa sul-africana de mineração Anglo-American, que começou a investir na indústria mineradora no Brasil em 1973 como parte da estratégia de driblar o isolamento do regime - um esforço que incluiu engajamento com outras ditaduras sul-americanas. ${ }^{11}$ Nos meados da década de 1980, a Anglo-American tinha comprado várias das maiores empresas mineradoras do Brasil e controlava $73 \%$ da produção de ouro no país, junto com $72 \%$ de seu níquel, $45 \%$ do nióbio, 33\% do tungstênio, $14 \%$ dos fosfatos, e $4 \%$ de sua prata. A Anglo-American também investiu na mineração de diamantes e no sector imobiliário. José Maria Pereira observou que "quem está realmente praticando uma diplomacia ativa é a África do Sul, não o Brasil." "12 A delegada na Assembleia Constituinte Benedita da Silva tentou sem sucesso de forjar uma aliança com delegados nacionalistas opostos o controle estrangeiro de recursos naturais para excluir a Anglo-American do Brasil.

\section{A visita de Mandela}

Dezoito meses depois de ser liberto, como parte do processo de desmantelamento do apartheid pelo governo de F.W. De Klerk, o ativista Nelson Mandela visitou ao Brasil. Embora a visita veio três anos antes das eleições que o faria presidente da África do Sul, já foi recebido como chefe de estado. Os objetivos da viagem de Mandela

10 José Maria Nunes Pereira, "O Apartheid e as relações Brasil-África do Sul.” Estudos Afro-Asiáticos, 14 (1987), 32-53, pp. 44-45.

11 Furlong, "The National Party of South Africa: A Transnational Perspective," in New Perspectives on the Transnational Right, eds. Martin Durham and Margaret Power. New York: Palgrave Macmillan, 2010, 73-74.

12 "Multinacionais monopolizam mineiração," Jornal de Brasília, 5 de abril de 1987, 9; José Maria Pereira, 47. 
eram vários: de manter a confiança no investimento estrangeiro na África do Sul, mostrando que a transição democrática na África do Sul seria um processo estável, e ao mesmo tempo manter pressão sobre o governo De Klerk para continuar o ritmo de mudanças. Do lado brasileiro, políticos e militantes negros tiveram objetivos distintos em relação à visita de Mandela. Ele manteve uma viagem intensa, com paradas no Rio de Janeiro, Espírito Santo, Bahia e Brasília. Governadores, prefeitos, deputados, senadores e o Presidente Collor organizaram uma agenda repleta de atividades públicas e privadas para associar-se à imagem do lider sul-africano.

Foi o governador do Rio de Janeiro, Leonel Brizola, quem mais se destacou no esforço de identificar-se com a imagem de Mandela. Parte da estratégia de Brizola para construir uma base política nacional para o Partido Democrático Trabalhista (PDT) era de incluir movimentos sociais como o movimento negro. Abdias do Nascimento e Caó ambos integraram o partido. Poucos meses antes da visita de Mandela, Brizola criou a Secretaria Extraordinária de Defesa e Promoção das Populações Afro-Brasileiras, e indicou Nascimento com seu primeiro diretor. Brizola fez da visita de Mandela ao Rio de Janeiro um festival: incluiu entre outros elementos um concerto no Sambódromo, e a inauguração do Centro Integrado de Educação Pública Nelson Mandela em Campo Grande.

Eventos da viagem de Mandela foram acompanhados por uma corrente de crítica por parte de militantes negros que ressentiam sua exclusão dos eventos com Mandela - de modo geral nem foram permitidos de compartilhar o palco público nem participar dos eventos privados. Desde fora dos eventos, militantes montaram protestos denunciando a discriminação no Brasil. Pior, Mandela elogiou o multi-racialismo brasileiro, dizendo que se sentia "em casa" e declarando que a experiência brasileira poderia servir como um exemplo para guiar o trabalho de criar uma sociedade multi-racial na África do Sul. Em vez de apoiar a luta pela igualdade ou servir como base para contestar a discriminação brasileira, a visita de Mandela encaixou na longa tradição de definir as relações raciais brasileiras como uma alternativa benigna às experiências dos Estados Unidos e da África do Sul. Como uma militante declarou, "Muitos torceram o nariz, pois estávamos no início do processo de demolição do perverso mito da democracia racial, que por muitos anos imobilizou a 
sociedade brasileira, impedindo um tratamento mais honesto das relações raciais e, sobretudo, punindo os negros." 13

Melissa Nobles argumenta que "depois da viagem de Mandela, militantes negros se acharam enfraquecidos... se encontraram na situação constrangedora de contradizer e ser contradito por Nelson Mandela. Militantes negros brasileiros tinham frequentemente usado a África do sul como ponto de comparação... Segundo suas caracterizações, o Brasil, como a África do Sul, era dirigida por uma minoria branca, mas pelo menos na África do Sul os negros assumiram seu racismo, e os negros, como negros, lutavam ativamente contra esse racismo." 14 Mas de certo modo os militantes estavam fortalecidos. A visita de Mandela repercutiu enormemente na mídia brasileira, e dentro da cobertura, houve disseminação intensa e nacional dos protestos contra a discriminação que aconteceram ao redor da viagem, tanto quanto o debate sobre o sentido da declaração de Mandela sobre as relações raciais brasileiras. Essa cobertura trouxe grande visibilidade ao movimento negro e à questão da desigualdade racial no Brasil. A revista Veja publicou um longo comentário comparando a qualidade de vida de negros no Brasil e na África do Sul, perguntando "quem discrimina mais?" O comentário concluiu que "O Brasil alinhou-se entre os países que aplicaram os castigos aos sul-africanos e fez bem, mas o fato é que em sua própria conta tem uma pesada fatura de injustiças e iniquidades. E se agora que o apartheid acabou invente-se de baixar sanções contra os países que distribuem mal a renda? E o caso se venha com a ideia de boicotar as nações que têm governos corruptos? Não é por nada não. É só para lembrar que o Brasil não está com essa bola toda para poder dar lições de moral à África do Sul."15

A visita de Mandela alimentou as duas percepções sobre a relação do Brasil com a África do Sul: sua calorosa recepção por

13 Dulce Maria Pereira, "Mandela é referência para afro-brasileiros," Folha de S. Paulo, May 30, 1999, I-25; há uma impressionante coleção de recortes de jornal sobre a visita de Mandela no site de Colin Darch, que na época da visita era pesquisador no Centro de Estudos AfroAsiáticos na Universidade Cândido Mendes: http://www.colindarch.info/mandela_no_brasil.php 14 Melissa Nobles, Shades of Citizenship: Race and the Census in Modern Brazilian Politics. Palo Alto: Stanford University Press, 2000, p. 157. $46-49$

15 Roberto Pompeu Toledo, "Casa Grande e Soweto," Veja, 31 de julho de 1991, pp. 
enormes públicos e de políticos serviu como base da percepção de que o Brasil seria um modelo para as relações raciais sul-africanas. Mas serviu também como um foro para denunciar a exclusão de grupos políticos negros da programação da visita, e elevou o perfil das críticas da desigualdade e da discriminação racial. Abidas do Nascimento repetiu sua declaração de FESTAC em 1977 de que o "apartheid do Brasil é muito pior do que a da África do Sul." ${ }^{\text {E }}$ E no final da viagem, Mandela tinha revisado suas declarações sobre relações raciais, observando "temos confiança que o povo brasileiro enfrentará corajosamente o problema do racismo no Brasil, como o povo americano o fez na década de 1960." Nobles explica que "com estas últimas palavras, o Brasil foi definido não como um país que já resolveu seu problema racial, mas como um país que ainda precisava enfrentá-lo. Era justamente este desmantelamento da narrativa de harmonia racial que a campanha [do movimento negro] procurava."17

No final, a visita de Mandela refletiu a persistente dificuldade em reconhecer a discriminação racial brasileira. O Estado de S. Paulo publicou um editorial no dia da chegada de Mandela que rejeitou a legitimidade do movimento negro e seus protestos. O editorial alertou que os protestos deveriam ser recebidos "com certa ressalva." Argumentou que o movimento negro era racista porque seus integrantes incorporavam "modismos que chegam dos Estados Unidos e batizando-se de afro-brasileiros." Citando Gilberto Freyre, chamou o conselho criado para levantar temas da comunidade negra no governo de São Paulo "lamentável," e sugeriu que a existência da Lei Afonso Arinos era o suficiente para fechar qualquer reivindicação de uma população que nem deveria ter identidade própria. ${ }^{18}$

Mas por outro lado, a visita refletiu o crescimento do movimento negro. Ao decorrer da visita, a imprensa brasileira relatou os protestos de militantes por fora dos eventos de Mandela. A reportagem seguia a mesma lógica: qualquer referência a militância negra enfatizava o pequeno número dos manifestantes, implicando que o movimento negro era pequeno, não representativo, e que sua

16 Citado em Nobles, 158.

17 Nobles, 158.

18 "Homenagens, com ressalva," ("Homages, with a note of caution"), $O$ Estado de $S$. Paulo, August 1, 1991, p. 3. 
agenda não merecia maior discussão. Mas por trás dos números, o que as reportagens revelam é a extensão da militância: os protestos ocorreram em todas as cidades visitadas por Mandela, refletindo um movimento que, embora não era nacional em sua organização, era nacional em sua extensão.

\section{Conclusão}

Em seu estudo do internacionalismo da Cuba revolucionária, Piero Gleijeses descreve o papel simbólico que a luta pela libertação da Argélia teve em Cuba na década de 1950. O regime de Fulgéncio Batista suprimia qualquer menção do movimento de Castro nos jornais, e relatos sobre a guerra na Argélia passaram a servir como alegoria do conflito Cubano. ${ }^{19}$ Para Glejeses, esta referência internacional para um conflito doméstico alimentou a criação de uma abordagem do governo revolucionário a colaborar com movimentos libertários no exterior, culminando nas operações militares em Angola que repeliram o exército sul-africano. A intervenção cubana ajudou a minar o "Total National Strategy" que sustentou os últimos anos do apartheid.

A luta contra o apartheid ocupou um lugar semelhante em países da América do Sul que saiam de ditaduras na década de 1980. $\mathrm{Na}$ Argentina, refletiu uma transição penosa. Em 1985, dois anos depois do fim do regime militar, o Presidente Raúl Alfonsín rompeu relações diplomáticas com a África do Sul no mesmo ano em que os integrantes das juntas militares que governaram entre 1976 e 1986 foram julgados. O sucessor de Alfonsín, Carlos Menem, restaurou relações com a África do Sul em 1991, entre medidas como o anulação das sentenças dos integrantes das juntas. No Chile, a ditadura de Augusto Pinochet (1973-1990) comprou armas da África do Sul. O processo de redemocratização Chilena veio tarde demais

19 Piero Gleijeses, Conflicting Missions: Havana, Washington, and Africa, 1959-1976. Chapel Hill: North Carolina, 2002, 31. 
para o novo regime impor sanções ou romper com o governo sulafricano, mas a Comissão Nacional da Verdade e Reconciliação chilena serviu como modelo para impor justiça na transição democrática na África do Sul.

Os projetos de redemocratização e da articulação de direitos humanos têm expressão global, mas fibra nacional. No Brasil a condenação do apartheid inevitavelmente repercutiu dentro do sistema de relações raciais e esteve conectado às mudanças nas políticas raciais que seguiram o fim do regime militar. Este artigo tem examinado as mudanças no sentido do apartheid dentro das relações raciais brasileiras, entendendo o conceito do apartheid no Brasil como uma expressão de debates sobre relações raciais brasileiras. O processo de democratização na África do Sul foi mais brusca e talvez mais completa que no Brasil, mas o apartheid, e a rejeição do apartheid, tem oferecido um espelho para afinar reflexões sobre a desigualdade racial e políticas de inclusão no Brasil.

RECEBIDO EM: 02/01/2016

APROVADO EM: 19/04/2016 